\title{
Radical Decomposition of Ether-Based Electrolytes for Li-S Batteries
}

\author{
Lucas Lodovico, ${ }^{\text {a,b }}$ Alberto Varzi, ${ }^{\mathrm{a}, \mathrm{b}, \mathrm{z}}$ and Stefano Passerini ${ }^{\mathrm{a}, \mathrm{b}, *, \mathrm{z}}$ \\ ${ }^{a}$ Helmholtz Institute Ulm (HIU), 89081 Ulm, Germany \\ ${ }^{b}$ Karlsruhe Institute of Technology (KIT), 76021 Karlsruhe, Germany
}

\begin{abstract}
In this work, the stability of ether-based electrolytes for Li-S batteries is investigated with particular regard to the effect of dissolved oxygen. Specifically, the performance of two different electrolyte solvents, i.e., 1,2-dimethoxyethane and its mixture with 1,3-dioxolane (DME:DOL, 1:1 v/v), is characterized in cells assembled in dry air environment, which would substantially lower production costs with respect to inert atmosphere (Ar). Although stability of all the components would suggest that Li-S batteries built in both the environments should behave similarly, it is found that cells containing the DME:DOL-based electrolyte are rather unstable in the presence of $\mathrm{O}_{2}$ in contrast to those employing DME-based electrolyte, which show a relatively good performance. The different sensitivity toward $\mathrm{O}_{2}$ of these electrolytes is associated to the ring-opening reaction of DOL, which happens to a greater extent when $\mathrm{O}_{2}$ is present, but occurs also in its absence. Based on these results a mechanism for electrolyte degradation in Li-S cells, and its reaction with dissolved polysulfides is proposed, which rationally explain for the first time the behavior already reported in literature for these kind of batteries. These findings are also relevant to the field of Li- $\mathrm{O}_{2}$ batteries, where these ether-based electrolytes are also used.

(C) The Author(s) 2017. Published by ECS. This is an open access article distributed under the terms of the Creative Commons Attribution 4.0 License (CC BY, http://creativecommons.org/licenses/by/4.0/), which permits unrestricted reuse of the work in any medium, provided the original work is properly cited. [DOI: 10.1149/2.0311709jes] All rights reserved.

(cc) BY
\end{abstract}

Manuscript submitted April 14, 2017; revised manuscript received May 24, 2017. Published June 21, 2017.

Sulfur has been extensively investigated as a new cathode material for secondary batteries, in order to replace metal oxides normally used in lithium-ion batteries (LIBs). The first point of interest is its high theoretical specific capacity, around $1672 \mathrm{mAh} \mathrm{g}^{-1}$, but, as a raw material sulfur is also non-toxic, readily available, and very inexpensive. It is indeed one of the main side products of crude oil refining, with more than 60 million tons produced annually. ${ }^{1}$ Even the relatively low operating voltage of sulfur-based cathodes, at around $2 \mathrm{~V} \mathrm{vs.} \mathrm{Li} / \mathrm{Li}^{+}$, can be considered as a potential advantage, making it intrinsically safer. ${ }^{2}$ Furthermore, the high specific gravimetric capacity of sulfur enables the remarkable specific energy of about $2600 \mathrm{~W} \mathrm{~h} \mathrm{~kg}^{-1}$. However, Lithium-Sulfur batteries (LSB) still present some specific challenges that need to be solved to enable their commercialization. ${ }^{2}$ First, sulfur has a very low electrical conductivity, around $5 \times 10^{-30} \mathrm{~S} \mathrm{~cm}^{-1}$ at $25^{\circ} \mathrm{C}$, requiring the introduction of a conductive matrix, normally carbon-based. The carbon host is generally electrochemically inert, such that it decreases the energy density of the electrode as whole, especially since it is often near to $50 \mathrm{wt} \%$ of the total sulfur-composite mass. Secondly, and most importantly, sulfur is a conversion material undergoing several chemical transformations during discharge and forming a variety of different polysulfides with the formal oxidation state of sulfur changing from 0 to -2 . Some of these intermediate species are soluble in the electrolyte, and very reactive toward both the electrolyte itself $f^{3,4}$ and the lithium metal anode. ${ }^{2,5}$ Most importantly though, their dissolution causes the loss of active material and, during charge, the so-called shuttle mechanism, i.e., the transfer of electrons from the negative to the positive electrodes. ${ }^{6,7}$ Finally, in the fully reduced state, $\mathrm{Li}_{2} \mathrm{~S}$ has low electrical and ionic conductivities, and is even less dense than sulfur. The poor conductivities result in the sulfide to be hardly re-oxidized, which leads to cell irreversibility and, in turn, capacity loss. The lower density means that, upon full reduction, the cathode volume increases, thus the sulfur electrode (i.e., the cell) must be capable of accommodating the volume expansion.

State-of-the-art LSBs' electrolytes are constituted by ether solvents, or a mixture thereof, ${ }^{3}$ a lithium salt, and, optionally, an additive..$^{8-10}$ The choice of ethers as solvent comes from their stability toward polysulfides. The superior chemical stability of ethers was also shown to be relevant for $\mathrm{Li}^{-} \mathrm{O}_{2}$ batteries, for instance. ${ }^{11} \mathrm{Sim}$ ilarly to $\mathrm{LSBs}$, $\mathrm{Li}-\mathrm{O}_{2}$ batteries rely on a conversion cathode (i.e., oxygen), which forms highly reactive intermediates that readily react with conventional carbonate-based electrolytes, leading to their

*Electrochemical Society Member.

${ }^{\mathrm{z} E-m a i l: ~ a l b e r t o . v a r z i @ k i t . e d u ; ~ s t e f a n o . p a s s e r i n i @ k i t . e d u ~}$ decomposition. This problem appears to be relieved in ether-based electrolytes.

Taking this in consideration, the electrochemistry of Li-S cells in a dry air environment is herein assessed. Building cells in dry air, in fact, could substantially lower production costs when compared to assembly in inert atmosphere (Ar). Although the stability of all the components would suggest that they should behave similarly in both cases, the effect of dissolved oxygen from dry air in the stateof-the-art electrolyte for LSBs (consisting of $1 \mathrm{~mol} \mathrm{~L}^{-1}$ LiTFSI and $0.25 \mathrm{~mol} \mathrm{~L}^{-1} \mathrm{LiNO}_{3}$ in a mixture of 1,2-dimethoxyethane and 1,3dioxolane (DME:DOL, 1:1 v/v)) and its role on the electrochemical stability of the battery, necessitate a deeper investigation. For comparative purposes, cells were also assembled using a similar electrolyte, containing only DME as solvent. Electrochemical and post mortem analysis allowed to develop a more detailed model of the chemical and electrochemical reactions that take place inside a LSB, as well as to determine which classes of solvents are less sensitive to the presence of air and could, therefore, enable the electrolyte filling step to be performed in non-inert (but still dry) environment.

\section{Methods}

Preparation of electrolytes.-Two sets of electrolytes were prepared and tested, one under dry air and one under argon (Figure S2). Electrolytes were prepared using 1,2-Dimethoxyethane (DME, Solvionic) and 1,3-Dioxolane (DOL, Solvionic) as solvents. Each solvent was dried using $20 \mathrm{wt} \%$ molecular sieve ( $3 \AA$, Alfa-Aesar) for $24 \mathrm{~h}$. The water content was reduced below $10 \mathrm{ppm}$ as determined by coulometric Karl Fischer titration (Mettler-Toledo Titrator Compact C30). For the DME:DOL-based electrolyte stored in dry air, the dried solvents were mixed in a 1:1 volumetric ratio, and the appropriate amount of lithium bis(trifluoromethanesulfonyl)imide (LiTFSI, battery grade $3 \mathrm{M})$ and lithium nitrate $\left(\mathrm{LiNO}_{3}\right.$, Alfa Aesar) were added, in order to achieve $1 \mathrm{~mol} \mathrm{~L}^{-1}$ and $0.25 \mathrm{~mol} \mathrm{~L}^{-1}$ concentrations, respectively. Dry DME was also used as the only solvent to prepare the electrolyte with the same LiTFSI and $\mathrm{LiNO}_{3}$ concentrations. The two electrolytes prepared and stored under dry air are hereinafter labeled as DME:DOL air and DME air. The same electrolytes compositions without exposition to air were also prepared as it follows. The dried solvents were degassed, each individually, via the Freeze-Pump-Thaw method. Briefly, each solvent was frozen in liquid nitrogen $\left(\mathrm{LN}_{2}\right)$ and then subjected to vacuum until a final pressure of less than $10^{-3} \mathrm{mbar}$ was achieved. The flask containing the solvent was than disconnected from the vacuum pump and allowed to melt under static vacuum. 
This step was repeated three times for each solvent. Afterwards, the solvents were transferred and stored in an Ar-filled glove-box (MBraun) with $\mathrm{O}_{2}$ and $\mathrm{H}_{2} \mathrm{O}$ content lower than $0.1 \mathrm{ppm}$. Dried and degassed DME and DOL were used to prepare the electrolyte solutions with the above-mentioned compositions. These electrolytes, prepared and stored under Ar, are labeled hereinafter as DME:DOL Ar and DME Ar.

Preparation of the sulfur cathode.-Sulfur composite cathodes (AC/S) were prepared by impregnation of sulfur in an activated carbon matrix. Specifically, $1 \mathrm{~g}$ of sulfur (Sigma-Aldrich) was dissolved in $65 \mathrm{~mL}$ of cyclohexane (Sigma Aldrich) at $70^{\circ} \mathrm{C}$ and added to $0.2 \mathrm{~g}$ of activated carbon (DLC Super30, Norit). The resulting slurry was sonicated for 40 minutes and further stirred for one hour at $60^{\circ} \mathrm{C}$, and for $24 \mathrm{~h}$ at $30^{\circ} \mathrm{C}$. The solid material was then filtered and dried at $50^{\circ} \mathrm{C}$ under vacuum to remove the solvent. The sulfur content was determined to be $52 \mathrm{wt} \%$ (Figure S1) by thermogravimetric analysis (TGA, Netsch) performed at a heating rate of $10^{\circ} \mathrm{C} \mathrm{min}{ }^{-1}$ in $\mathrm{N}_{2}$ atmosphere, from $80^{\circ} \mathrm{C}$ to $500^{\circ} \mathrm{C}$. The weight percent of sulfur was calculated as the difference between the initial and the final mass of the composite, i.e., assuming that only but all sulfur sublimated by heating.

The AC/S composite was then mixed with polyvinylidene fluoride (PVdF 6020, Solvay) and SuperC65 (Imerys Graphite \& Carbon), as binder and conductive carbon, respectively, in the ratio of 85:5:10. N-Methyl-2-pyrrolidone (NMP, Sigma Aldrich) was used as solvent to prepare the slurry. Electrodes were cast onto aluminum foils using the Doctor blade method. The electrode layer was firstly dried at $60^{\circ} \mathrm{C}$ under normal atmosphere to remove the solvent and then punched into $12 \mathrm{~mm}$ diameter discs. Finally, the electrode disks were further dried overnight at $50^{\circ} \mathrm{C}$ in vacuum to remove solvent and water traces before being used for the electrochemical characterization. The final sulfur mass loading of the electrodes was $\sim 1 \mathrm{mg}_{\mathrm{s}} \mathrm{cm}^{-2}$.

Electrochemical characterization.-Three-electrode, Swageloktype T-cells were assembled inside an Ar-filled glove box $\left(\mathrm{O}_{2}\right.$ and $\mathrm{H}_{2} \mathrm{O}<0.1 \mathrm{ppm}$ ), using AC/S composite disk as working electrode, 12-mm disk lithium metal (Albemarle) as anode, and a lithium metal strip as reference electrode. Glass fiber discs (Whatman GF/A) were used as separator, soaked with $\sim 100 \mu \mathrm{L}$ of electrolyte. To prevent short-circuits, four layers of glass fiber were used between the counter and working electrodes. The reference electrode consisted of a thin strip of lithium attached to a $\mathrm{Ni}$ grid, with $2 \mathrm{~mm}$ length, inserted in-between the four separator layers.

Cells with electrolytes under Ar were assembled inside the glove box. The $\mathrm{O}_{2}$ containing electrolytes were sealed inside a bubble-free blister, and brought inside the glove box. Once inside, the blister was punctured using a syringe needle, and the extracted electrolyte quickly added to the separator, and the cell sealed, to avoid gas exchange with the argon environment.

All galvanostatic measurements were performed at a constant rate of $\mathrm{C} / 10\left(1 \mathrm{C}=1675 \mathrm{~mA} \mathrm{~g}_{\mathrm{s}}{ }^{-1}\right)$ between 3.0 and $1.5 \mathrm{~V}$ vs $\mathrm{Li} / \mathrm{Li}^{+}$ using a Modulab XM ECS (Solartron Analytical). After each cycle, the sulfur electrodes were held at $3.0 \mathrm{~V}$ for 20 minutes to ensure full delithiation of the cathode and bring the system to a stable condition (the current typically dropped below $\mathrm{C} / 30$ ) and analyzed by potentiostatic electrochemical impedance spectroscopy (EIS), from $250 \mathrm{kHz}$ to $10 \mathrm{mHz}$, with a sinus amplitude of $5 \mathrm{mV}$. All tests were performed in a climatic chamber at $20^{\circ} \mathrm{C}$ (Binder). Each cell was run for a total of 10 discharge/charge cycles and, finally stopped in the charged state $\left(3.0 \mathrm{~V} \mathrm{vs} \mathrm{Li} / \mathrm{Li}^{+}\right)$for the post mortem analysis.

Post mortem analysis. - After cycling, all cells were disassembled inside an Ar-filled glove box. The sulfur cathodes were gently but carefully washed with DME to remove any salt residue, and stored under Ar. To recover the electrolyte, the separators were placed inside a sealed vial and centrifuged at $6000 \mathrm{rpm}$ for $60 \mathrm{~min}$.

The cathodes were subjected to scanning electron microscopy (SEM, Zeiss LEO $1550 \mathrm{VP}$ ), with an acceleration voltage of $3 \mathrm{kV}$. To avoid any contamination by air, all samples were transferred inside the SEM chamber using a sealed sample carrier filled with Ar.

The cathodes were also analyzed by X-ray photoelectron spectroscopy (XPS, PHI 5800 MultiTechnique ESCA System, Physical Electronics), using a monochromatic Al-K $\alpha(1486.6 \mathrm{eV})$ radiation. The measurements were performed with a detection angle of $45^{\circ}$, using pass energies at the analyzer of 93.9 and $29.35 \mathrm{eV}$ for survey and detail spectra, respectively. The samples were transferred to the device using a sealed sample carrier to avoid air contamination. All XPS spectra were calibrated to the signal of the $\mathrm{C}(1 \mathrm{~s})$ peak at $284.6 \mathrm{eV}$ and analyzed using CasaXPS software. For the analysis of the sulfur spectra, the $S\left(2 p_{1 / 2}\right)$ peaks were constrained to be shifted $+1.16 \mathrm{eV}$ with respect to the corresponding $S\left(2 p_{3 / 2}\right)$ peaks, while having 0.511 times their area, and the same full width at half maximum (FWHM).

Both the fresh electrolytes and those recovered from cycled cells were analyzed by infrared spectroscopy (IR, PerkinElmer) in the attenuated total reflectance (ATR) mode. All ATR-IR measurements were performed in dry argon atmosphere (glove box).

\section{Results and Discussion}

Figures 1a and 1c have very similar voltage profiles, in agreement with the typically poor cycling behavior of sulfur cathodes. ${ }^{12}$ The discharge profile consists of a plateau at ca. $2.4 \mathrm{~V}$, a sloping region from ca. 2.3 to $2.1 \mathrm{~V}$, and another, longer, plateau at ca. $2.1 \mathrm{~V}$. The high voltage plateau at $2.4 \mathrm{~V}$ is due to the reduction of $\mathrm{S}_{8}$ to high order polysulfides $\left(\mathrm{Li}_{2} \mathrm{~S}_{6-8}\right)$. In the sloping region, these are reduced to form shorter polysulfides $\left(\mathrm{Li}_{2} \mathrm{~S}_{4}\right)$, which are further reduced at ca. $2.1 \mathrm{~V}$ to solid $\mathrm{Li}_{2} \mathrm{~S}_{2}$ and $\mathrm{Li}_{2} \mathrm{~S}$, i.e., the final discharge products. It is important to note, however, that many disproportionation reactions take place in such a system, and the exact nature of the formed species upon reduction is still not fully known. ${ }^{12,13}$ The abovementioned species represent what the average chain length is expected to be in each case. Finally, the last plateau at ca. $1.7 \mathrm{~V}$ is probably associated to the irreversible reduction of $\mathrm{LiNO}_{3}$ on the positive electrode, ${ }^{14}$ which eventually vanishes due its complete consumption upon cycling.

Interestingly, the presence of air in the electrolyte appears to be less relevant for the electrolyte based on DME as the only solvent, as testified by the similar voltage profiles of the cells employing DME $\mathrm{Ar}$ and DME air (Figures 1a and 1b, respectively), although with a higher fading of the latter. A first feature to be noticed is the lack of any sign of oxygen reduction in the DME air electrolyte. Oxygen reduction should be expected at about $2.6-2.7 \mathrm{~V} \mathrm{vs} \mathrm{Li/Li}{ }^{+},{ }^{15,16}$ while in Figure 1b, no plateau at this potential is detected. This is, however, not surprising, since most of the $\mathrm{O}_{2}$ is likely reacting with the lithium anode, as soon as the cell is assembled. The only indication of $\mathrm{O}_{2}$ presence is the slightly higher open circuit potential (OCP) before the experiment started (ca. $3.3 \mathrm{~V}$ in air vs ca. $2.8 \mathrm{~V}$ in Ar), possibly due to the reaction of sulfur with oxygen, forming lower sulfur oxides. Such oxides might explain the higher OCP observed in this case.

A further substantial difference between DME Ar and DME air is the more pronounced capacity fading of the latter (see Figure 1e). A possible explanation would be the oxidative decomposition of DME, which can form, among other, inorganic carbonates and esters. ${ }^{17}$ Sulfides and polysulfides are known for their high nucleophilicity, in part due to the large atomic volume of sulfur, making them readily polarizable. Organic thiolates, which have a negatively charged sulfur atom analogous to sulfides and polysulfides, have been shown to be highly reactive toward organic esters, ${ }^{18}$ resulting in their cleavage. Therefore it is not unlikely that polysulfides formed during discharge of sulfur cathodes can also react with organic carbonates via nucleophilic attack, ${ }^{4}$ forming (poly)-thioesters. Hence, the carbonates and esters formed by oxidation of DME in presence of air are expected to react with dissolved polysulfides formed during discharge, decreasing the available amount of active material and, in turn, leading to a more pronounced capacity fade in each cycle, when compared to the air-free DME electrolyte.

DME:DOL air (see Figure 1d), on the other hand, shows a rather different behavior compared to the DME:DOL Ar. The first cycle 

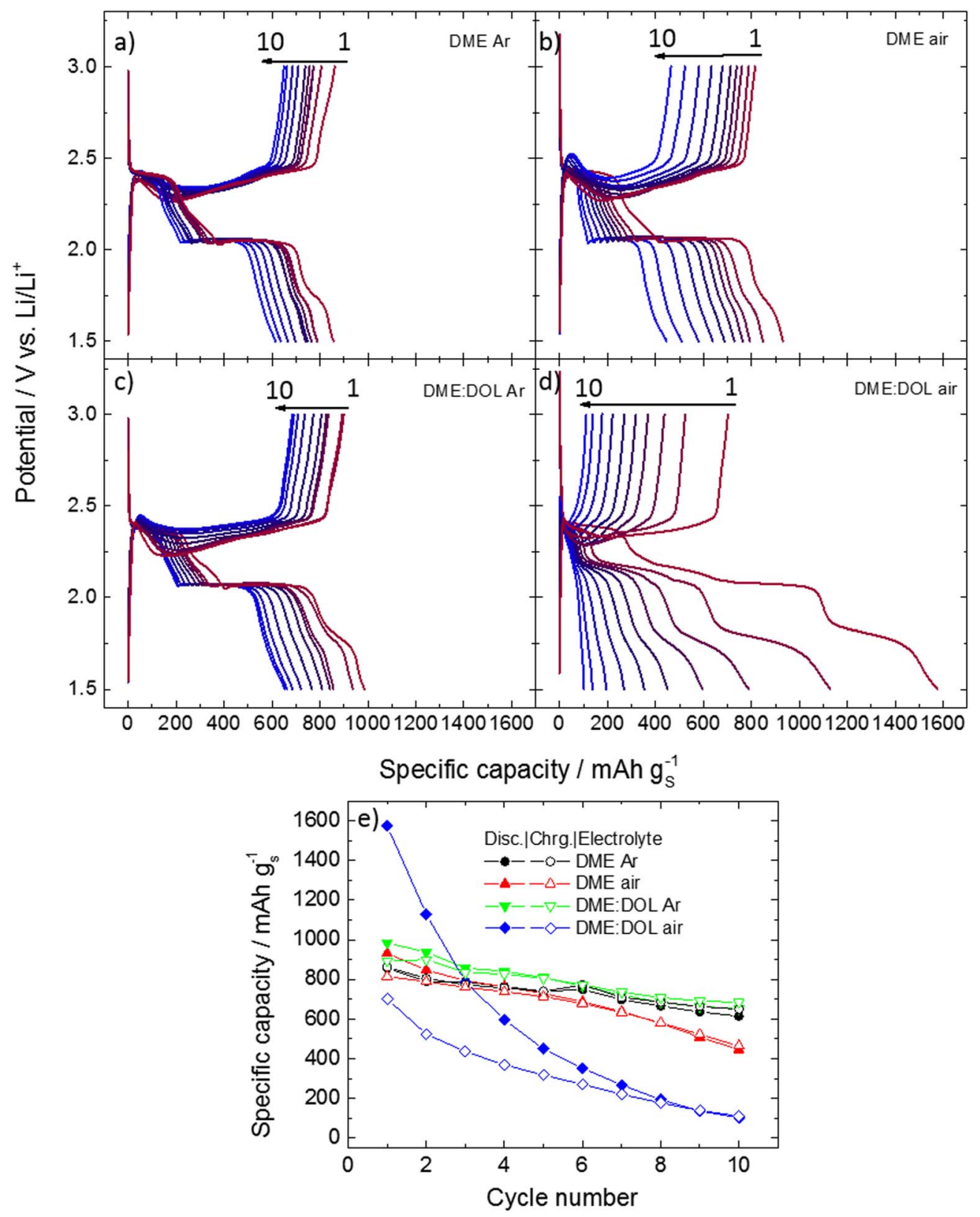

Figure 1. Voltage profiles of Li-S cells with different electrolytes: (a) DME Ar, (b) DME air, (c) DME:DOL Ar, and (d) DME:DOL air. (e) Capacity retention upon 10 cycles of the Li-S cells employing different electrolytes.

capacity is much larger (ca. $1600 \mathrm{mAh} \mathrm{g}_{\mathrm{s}}^{-1}$ ) than with any other electrolyte investigated herein. This is mainly due to the increased discharge capacity in the sloping region comprised between 2.25 and $2.08 \mathrm{~V}$ (see Figure S3), and to the higher charge arising from nitrate reduction, accounting for a respective increase of capacity, in these regions, of $178 \%$ and $116 \%$, with respect to the other electrolytes. This higher discharge capacity of nitrate is likely associated to larger availability of nitrate in the electrolyte. As it will be shown later, indeed, the passivation of the lithium anode by the decomposition products of DOL results in the lower consumption of nitrate at the anode, making it available to react on the positive electrode. Once again, no feature attributable to oxygen reduction could be observed besides the higher initial OCP value. The Coulombic efficiency of the cell also decreases substantially, with approximately half the capacity being lost in the first charge. After 10 cycles, the capacity of the cell employing DME:DOL air is only $110 \mathrm{mAh} \mathrm{g}_{\mathrm{s}}{ }^{-1}$ while the typical plateaus of sulfur are practically vanished.
Figure 2 shows the differential capacity plots of the discharge curves for the cells employing the various electrolytes. A characteristic that particularly stands out is the peak between 2.3 and $2.1 \mathrm{~V}$ vs. $\mathrm{Li} / \mathrm{Li}^{+}$, corresponding to the sloping region in Figures 1a-1d. Such feature is much more evident when DME:DOL air is used as electrolyte. For DME:DOL Ar, in fact, only the first cycle shows a more prominent feature, rapidly decreasing for subsequent cycles. Similar results were shown in literature for solvents with a large concentration of the trisulfur radical anion, ${ }^{19}$ indicating that the amount of trisulfur radical might also be higher in the abovementioned cases.

As displayed in Figure 3, the pristine and cycled electrolytes were analyzed by ATR-IR. The dashed vertical lines mark two regions of interest for these electrolytes being solely associated to either DME or DOL. The bands around $1454 \mathrm{~cm}^{-1}$ are due to the asymmetric deformation of the methyl group $\left(-\mathrm{CH}_{3}\right)$ in DME, ${ }^{20}$ as confirmed by their absence in the spectrum of pure DOL too (labeled as 'DOL electrolyte' in Figure 3a). The band around $960 \mathrm{~cm}^{-1}$ is, instead, 


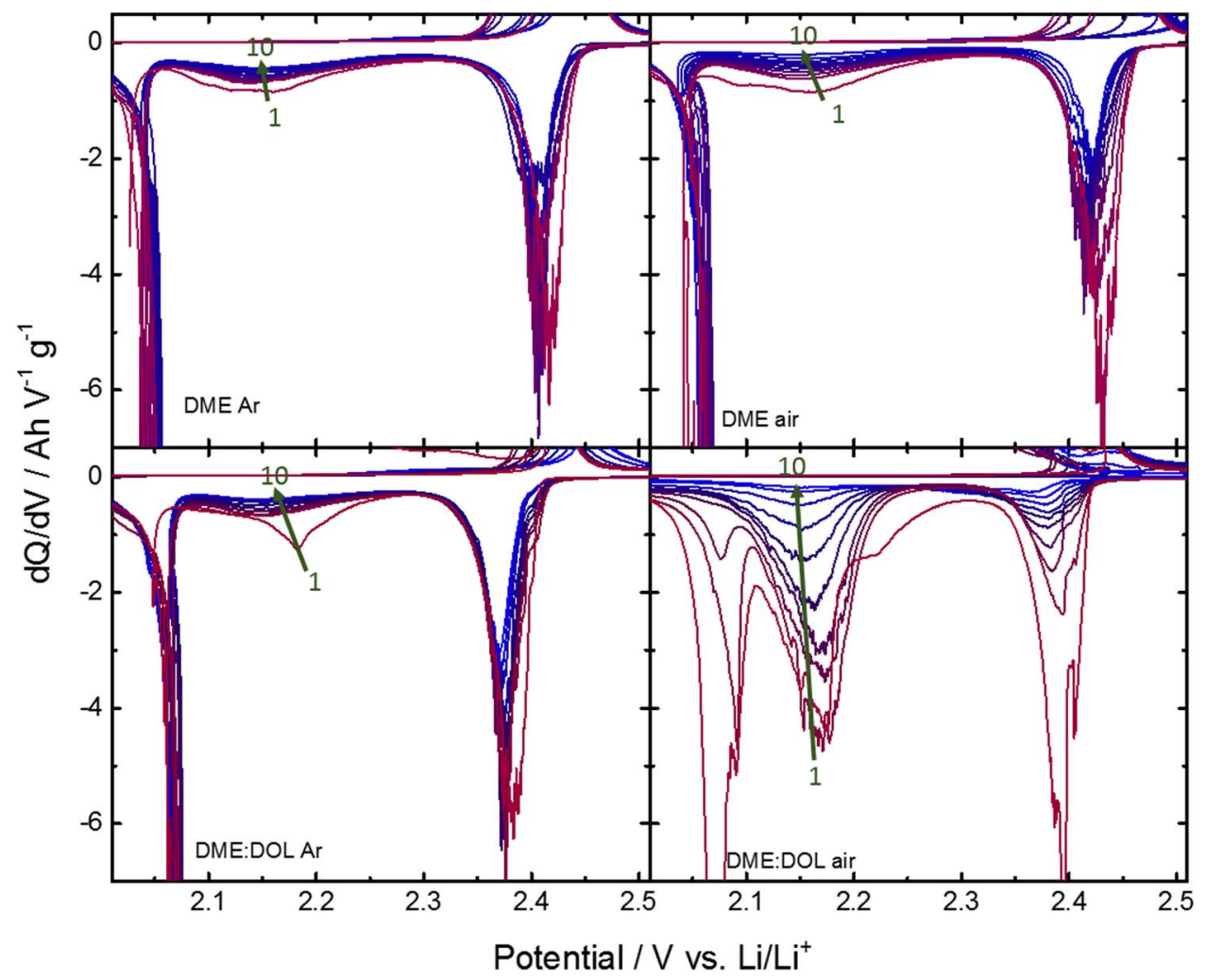

Figure 2. Differential capacity plots of the discharge curves (reported in Figure 1a-1d) of cells with a) DME Ar, b) DME air, c) DME:DOL Ar, and d) DME:DOL air electrolytes. The plots are focused in the region of major interest, i.e. between 2.0 and $2.5 \mathrm{~V} \mathrm{vs} \mathrm{Li} / \mathrm{Li}^{+}$.

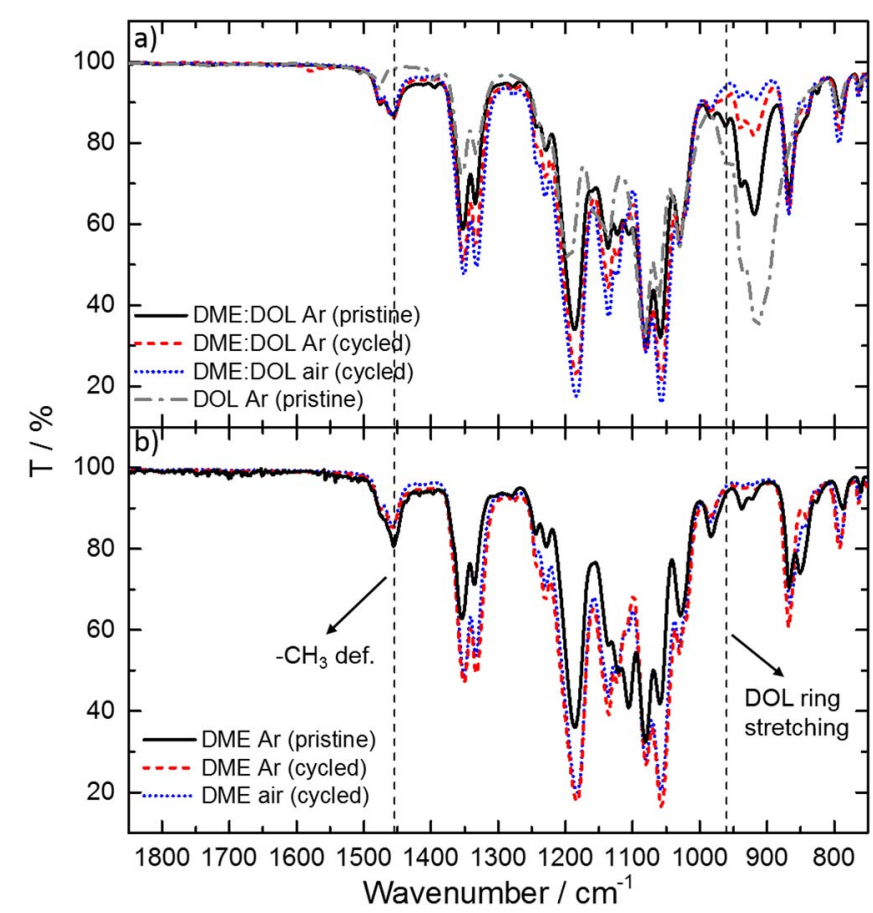

Figure 3. ATR-IR spectra of the different electrolytes: a) DME:DOL Ar (pristine), compared to DME:DOL Ar after 10 cycles (DME:DOL Ar (cycled)), DME:DOL air after 10 cycles (DME:DOL air (cycled)), and a solution of $1 \mathrm{~mol} \mathrm{~L}^{-1}$ LiTFSI and $0.25 \mathrm{~mol} \mathrm{~L}^{-1} \mathrm{LiNO}_{3}$ in DOL (DOL Ar); b) DME Ar (pristine), compared to DME Ar after 10 cycles (DME Ar (cycled)), and DME air after 10 cycles (DME air (cycled)). due to the ring stretching of DOL, ${ }^{21}$ and is therefore absent in the DME-based electrolyte.

From Figure 3, it is clear that DOL is consumed during cycling. The decrease of the DOL band upon cycling is stronger when oxygen is present, but it is also appreciated in the DME:DOL Ar electrolyte. Differently, the DME band is not strongly affected in any case. These findings are in agreement with those previously observed in Figure 1. Namely, oxygen has a stronger impact on DOL. The oxygen solubility in DME:DOL is similar to that in DME, calculated to be around 1.5 mmol L ${ }^{-1}$ in both electrolytes, ${ }^{22}$ i.e., a higher amount of dissolved $\mathrm{O}_{2}$ is not the reason for the increased decomposition. Thus, the decomposition mechanisms of DME and DOL must be different. As a matter of fact, it has been shown that DME reacts with oxygen superoxide to form esters, by bonding oxygen atoms to the carbon backbone of DME. ${ }^{17}$ By this mechanism, oxygen is consumed upon oxidation of DME, i.e., the decomposition will stop after all $\mathrm{O}_{2}$ has reacted. Differently, being a cyclic compound, DOL is unsaturated and subject to ring opening reactions (ROR) leading to polymerization ${ }^{23,24}$ and isomerization..$^{25}$

Figure 4 depicts the proposed DOL decomposition mechanism in Li-S cells. Although we could not directly detect the presence of radicals, it is known from literature that they can start decomposition reactions of DOL, ${ }^{25}$ so three sources of radicals are proposed: reduction of $\mathrm{O}_{2}$ to form superoxide radical (when air is present), nitrate reduction products, and trisulfur radical anion (Figures $4 \mathrm{a}-4 \mathrm{c}$, respectively). Of particular importance is the reduction of $\mathrm{O}_{2}$, when present, in contact with metallic lithium, leading to the formation of lithium superoxide (Figure 4a). This species is known to be highly reactive, and, in fact, causes the increased DOL consumption when $\mathrm{O}_{2}$ is present. From Figure 3, it is obvious that some DOL is consumed even in the absence of $\mathrm{O}_{2}$, meaning that some other radical sources must be inherently present in the cell, forming radicals which are less reactive and/or in a smaller amount. For example, the electrolyte also contains $\mathrm{LiNO}_{3}$ to aid the solid electrolyte interphase (SEI) formation on the lithium anode. ${ }^{10,26}$ The mechanism of nitrate reduction 


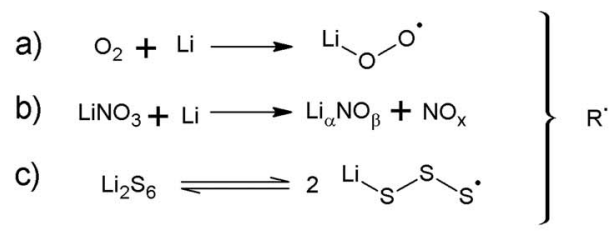

d)

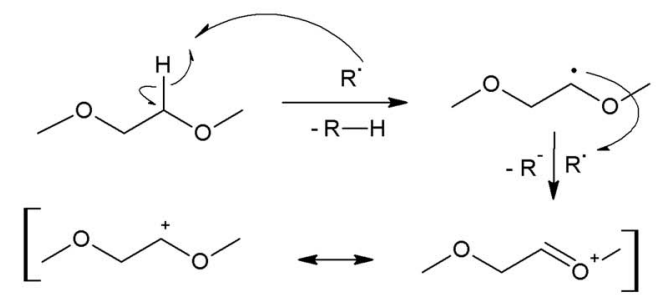

e)
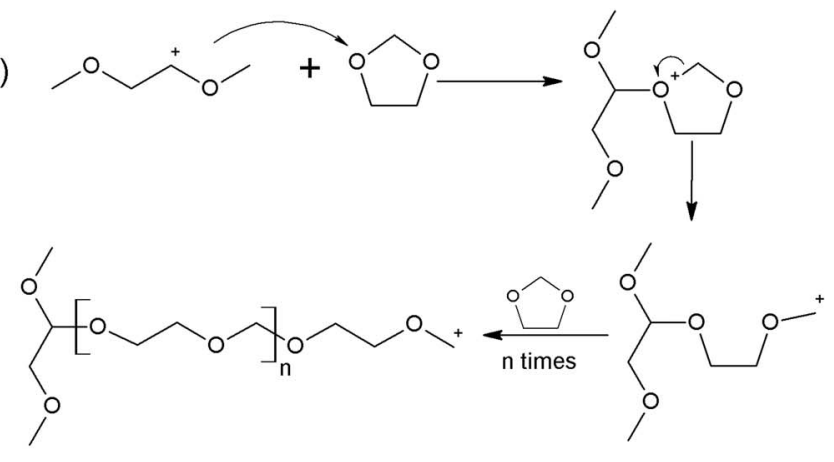

f)

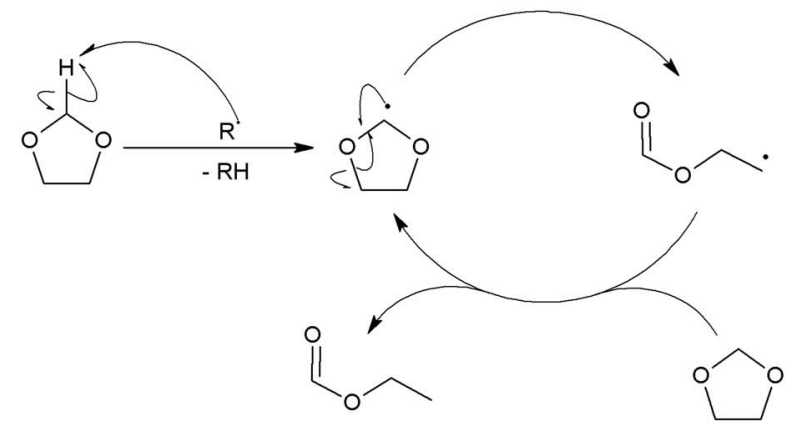

Figure 4. Proposed mechanisms of (a-c) radical formation in Li-S cells, (d-e) DOL polymerization, and (f) DOL isomerization.

in these electrolytes has not been fully elucidated yet, as studies on the subject often show only the decomposition products of $\mathrm{LiNO}_{3}$ over the lithium surface. ${ }^{10}$ However, there has been some studies on nitrate reduction in molten-salt electrolytes ${ }^{27}$ where the reduction occurs through the formation of lower nitrogen oxides and alkali metal oxides. Since ether-based electrolytes are aprotic, it is expected that the reduction of $\mathrm{LiNO}_{3}$ follows a mechanism close to that occurring in molten salts (Figure 4b). Lastly, the presence of $\mathrm{LiS}_{3}{ }^{\bullet}$ is inherent of Li-S cells ${ }^{12,19}$ (Figure 4c), and this radical could also react with the solvent.

Given the presence of radicals granted, the first mechanism for DOL decomposition is its polymerization, as shown in Figures $4 \mathrm{~d}$ and 4e. It has been shown that DOL polymerization occurs neither through anionic ${ }^{24}$ nor radical initiators, ${ }^{25}$ but only via cationic polymerization. Thus, we propose a mechanism where the radicals in solution react with DME to form a carbocation (Figure 4d), which then reacts with DOL to start the polymerization (Figure 4e). Additionally, there might be other Lewis acids in solution, which could help initiating the polymerization as well. Polymerization of DOL has been already shown in $\mathrm{Li}-\mathrm{O}_{2}$ batteries, i.e., where molecular oxygen is present and dissolved in the electrolyte, ${ }^{17,28}$ as well as LSB. ${ }^{26}$ Aurbach and coworkers ${ }^{28}$ showed, for instance, that a silver electrode swept from 3.0 to $1.7 \mathrm{~V}$ vs $\mathrm{Li} / \mathrm{Li}^{+}$in a $0.5 \mathrm{~mol} \mathrm{~L}^{-1}$ solution of $\mathrm{LiClO}_{4}$ in DOL do not show any polymerization product over its surface. For the same system with added $\mathrm{O}_{2}$, some polyether species are detected on the silver surface by FTIR, showing that the products of $\mathrm{O}_{2}$ reduction can indeed promote DOL polymerization, although the specific mechanism of polymerization in this setup was not determined. A similar phenomenon was reported by Bruce and coworkers ${ }^{17}$ in $1 \mathrm{~mol} \mathrm{~L}^{-1} \mathrm{LiPF}_{6}$ in DOL under 1 atm $\mathrm{O}_{2}$, although the excess of oxygen lead to further oxidation of polyether to form polyesters. In another work by Aurbach and coworkers, ${ }^{29}$ lithium metal was exposed to pure DOL and DOLbased electrolytes (without oxygen). FTIR and XPS measurements of the surface of lithium showed hints for DOL decomposition, among which some peaks related to $\mathrm{C}-\mathrm{O}$ bonds that the authors attributed to both polyether and alkoxide species. This is agreement with our findings reported in Figure 3a, in which DOL is consumed even when the electrolyte has no oxygen dissolved. Overall, all these previous reports are also in accordance with Figures $4 \mathrm{a}$ and $4 \mathrm{~b}$, where we show that DOL decomposition starts on the anode side. Interestingly, the last work by Aurbach et al. ${ }^{29}$ also showed the presence of formate on the surface of lithium, which supports the reaction mechanism in Figure $4 \mathrm{f}$, where direct reaction of DOL with radical species does not involve polymerization, but rather its isomerization to form ethyl formate. ${ }^{25}$ This reaction is explained by the formation of a (strong) $\mathrm{C}=\mathrm{O}$ bond, and takes place in parallel to the polymerization.

The formation of a polymeric film over the anode has a potentially good impact on the cell cycle life, since it avoids the reaction of polysulfides with metallic lithium. In fact, this might be one of the reasons for the early reports on DOL-containing electrolytes offering better performance, ${ }^{3,30,31}$ as those did not use SEI forming additives (e.g., $\left.\mathrm{LiNO}_{3}\right){ }^{32}$ The presence of ethyl formate appears to be, however, very detrimental to the cell cycling life, since polysulfides can react with esters, ${ }^{4,18}$ forming electrochemically inert products.

According to the above-mentioned processes, Figure 5 shows the proposed mechanism which could explain the higher capacity observed in the sloping region (Figures 1 and 2). Ordinarily, only the reduction of $\mathrm{S}_{8}{ }^{2-}$ to form $\mathrm{S}_{4}{ }^{2-}$ is expected to happen extensively in this region. In fact, the $\mathrm{S}_{8}{ }^{2-}$ disproportionation to form $\mathrm{S}_{6}{ }^{2-}\left(\mathrm{S}_{3}{ }^{\bullet-}\right)$ and solid $\mathrm{S}_{8}$, was shown to be slow. ${ }^{19}$ The results shown in Figure 2 suggest, however, that $\mathrm{S}_{8}{ }^{2-}$ reacts to form a (poly-thio)ester in the presence of an ester. This (poly-thio)ester is then reduced, forming the stable trisulfur radical anion and a thiocarboxylic radical, which is also stabilized by resonance. These two products are further reduced in the same voltage range resulting in the increased capacities observed in Figure 2. Interestingly, the IR spectra of the electrolytes after cycling (Figure 3) do not show peaks assignable to the carbonyl group. This suggests that the formed products are not present in solution. Since the products are not dissolved in the electrolyte, it follows that they must be insoluble in the ether-based electrolytes and are deposited on the electrodes. In order to support this hypothesis, EIS measurements were performed.

Figure 6a shows the Nyquist plots of AC/S cathodes (charged state) recorded during the initial 10 cycles in the various electrolytes while Figure $6 \mathrm{~b}$ shows their magnification of the high-frequency region. The impedance spectra of the charged AC/S electrodes in DME Ar, DME air, and DME:DOL Ar, are very similar. They all show a depressed semi-circle in the high frequency region (see magnifications in Figure $6 b$ ) followed by a capacitive- and diffusion-related feature in the midand low-frequency regions. The impedance spectra of $\mathrm{AC} / \mathrm{S}$ electrode in DME:DOL air, however, are remarkably different, showing a much larger high-frequency semi-circle as well as the appearance of a second semicircle. Both features rapidly grow upon cycling. Overall, the impedance spectra resemble the trend seen in Figure 1, in that the electrochemical behavior of the AC/S electrode in the DME:DOL air electrolytes is rather different than in the other electrolytes (which are rather comparable to each other).

The high-frequency semi-circle is obviously associated to the electrode-electrolyte interface, being depressed by the porous electrode morphology and, possibly, the presence of a passive layer. ${ }^{33}$ 


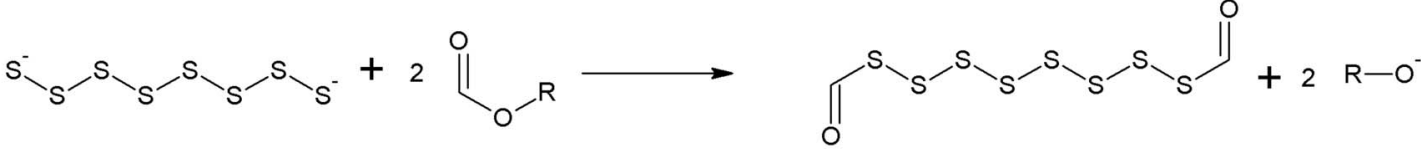

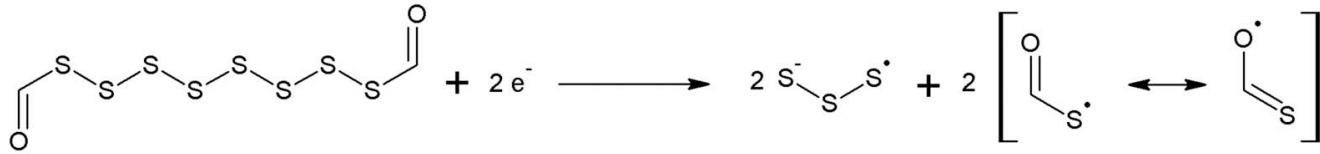

$$
\begin{aligned}
& {\stackrel{O}{S^{*}}}^{\longrightarrow}+\mathrm{e}_{\mathrm{S}^{-}}^{\mathrm{O}} \\
& s_{S^{-}} s^{0}+e^{-} \longrightarrow s_{S^{-}}^{-} s^{-}
\end{aligned}
$$

Figure 5. Proposed mechanism of sulfur reduction in the presence of ester, on the region between 2.3 and $2.1 \mathrm{~V} \mathrm{vs} \mathrm{Li}_{/} / \mathrm{Li}^{+}$.
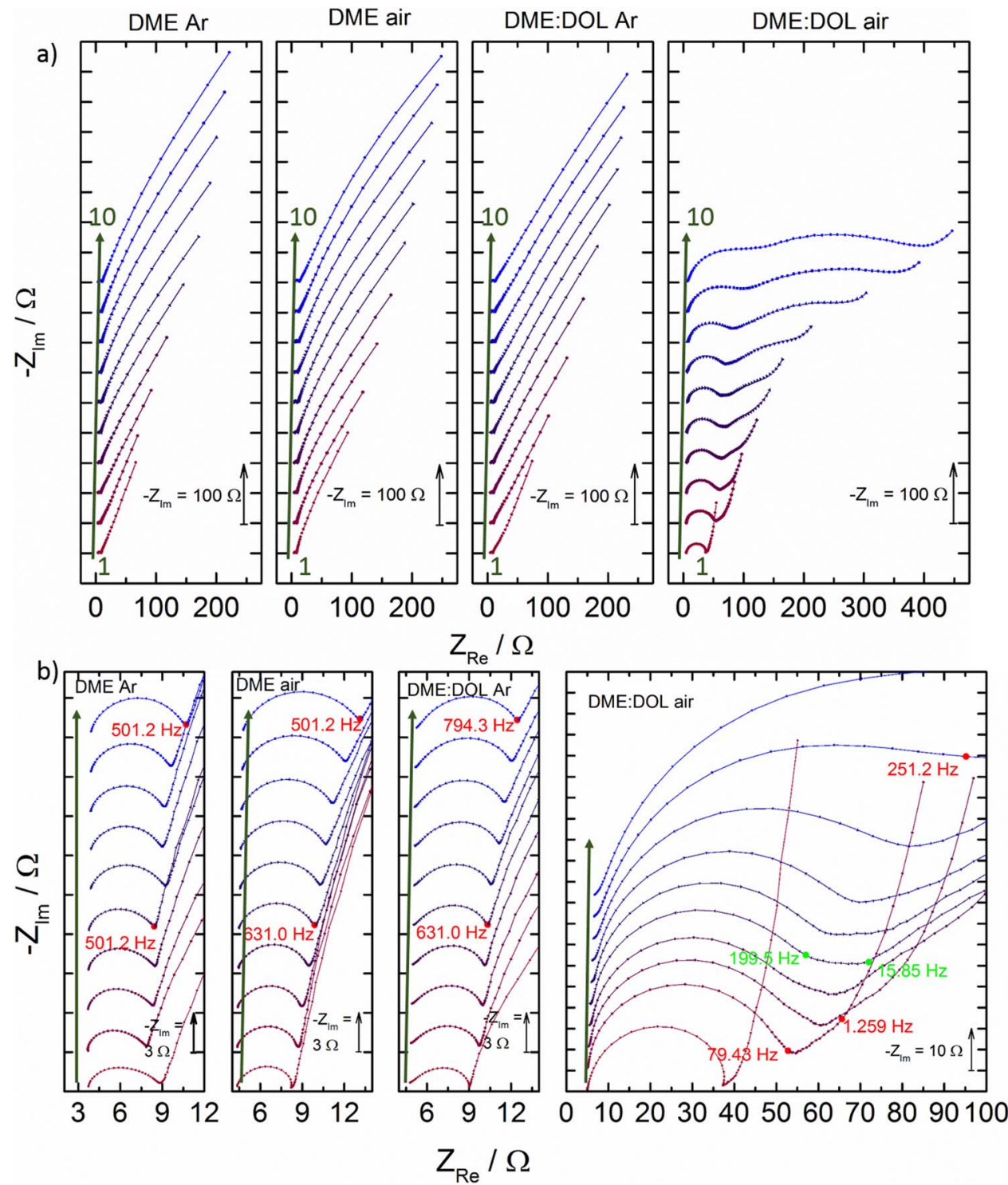

Figure 6. a) EIS spectra of $\mathrm{AC} / \mathrm{S}$ cathodes at $3.0 \mathrm{~V}$ vs $\mathrm{Li} / \mathrm{Li}^{+}$for the four different kinds of electrolytes, and b) magnification of the high frequency region of said spectra, with frequencies of interest highlighted. The arrow on the left of each panel indicates the spectrum series, from the 1st to the 10th cycle. The highlighted points are an indication to the reader of the frequency range at which each element is observed. 
S

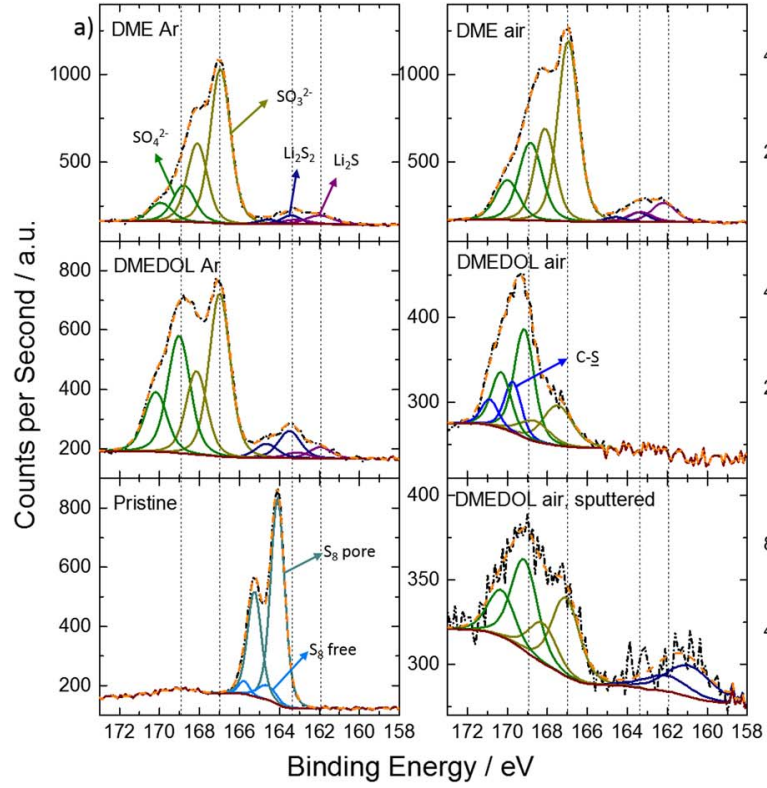

C

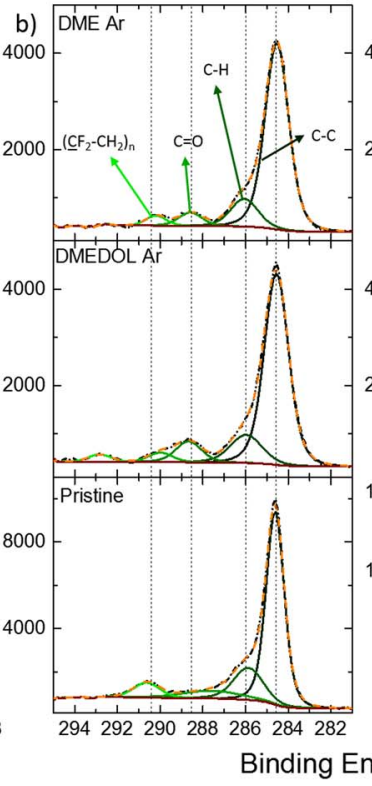
DME air

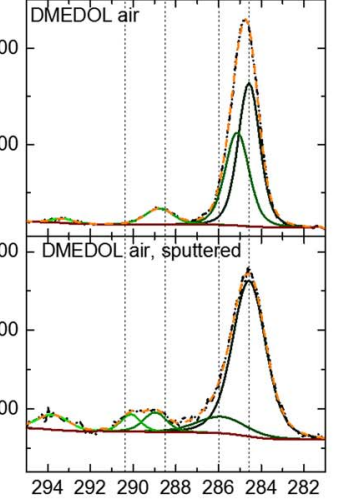

rgy / eV

Figure 7. XPS spectra of a) sulfur, and b) carbon for charged AC/S electrodes ( $3.0 \mathrm{~V}$ vs $\left.\mathrm{Li} / \mathrm{Li}^{+}\right)$after cycling in the various electrolytes. The XPS spectra of the pristine electrodes are also shown for comparison. The cathode exposed to DME:DOL air was also sputtered for 2 minutes to remove the top layer. Black lines: raw data, brown lines: background, orange dashed lines: spectral envelopes.

As a matter of the fact, this high-frequency feature is seen to increase upon cycling as the result of the passive layer growth. The rather larger diameter of this feature observed for the electrode in DME:DOL air already at the end of the $1^{\text {st }}$ cycle, is clearly indicative of a thicker passive layer and, consequently, pore-clogging. Upon further cycling in this electrolyte, however, another depressed semi-circle appears in the mid-frequency range, which rapidly increases upon further cycling. The rapid evolution of both features may be associated with the reduction of sulfur in DME:DOL air leading to the formation of solid thio-carboxylates (see Figure 5), which are insoluble and precipitate initially at the electrode/electrolyte interface inside the porous electrode (pore clogging) and final over the electrode itself, causing the appearance of the second semi-circle. Such a rapid increase of the electrode impedance matches very well with the fast fading observed in Figure 1.

The evolution of the Li electrode impedance (Figures S4 and S5) confirms as the reactions of DOL start at the anode side, as the results suggest formation of a thick film over the lithium metal even before the cell started cycling, which is in accordance with the mechanism in Figures $4 \mathrm{a}, 4 \mathrm{~b}$, and $4 \mathrm{e}$. The formed ester, however, dissolves into the electrolyte and migrates to the cathode where it reacts with the polysulfides forming solid deposits onto the $\mathrm{AC} / \mathrm{S}$ cathode, thus explaining the rapid impedance increase upon cycling.

The AC/S cathodes were analyzed by SEM to check for morphological differences evolving upon cycling. As shown in Figure S6, while the activated carbon particles present in the pristine electrodes are still observable in the cathodes cycled in DME Ar, DME air, and DME:DOL Ar, the electrode operated in DME:DOL air is clearly different, showing a thick deposit of undefined morphology, and no distinguishable AC particles. This corroborates the EIS results reported in Figure 6, showing the growth of a thick passivation layer over the electrode.

Figure 7 shows the XPS spectra of the pristine and cycled (charged state) AC/S cathodes. The sulfur spectrum of the pristine cathode consists mostly of sulfur trapped inside AC pores $\left(\mathrm{S} \mathrm{2} \mathrm{p}_{3 / 2} 164.1 \mathrm{eV}\right)^{33}$ and some small amount of free sulfur $\left(\mathrm{S} 2 \mathrm{p}_{3 / 2} 164.6 \mathrm{eV}\right){ }^{34}$ The carbon spectrum of the pristine electrode displays peaks for $\mathrm{C}-\mathrm{C}$ bonds $(\mathrm{C} 1 \mathrm{~s}$ $284.6 \mathrm{eV}), \mathrm{C}-\mathrm{H}(\mathrm{C} 1 \mathrm{~s} 285.9 \mathrm{eV}), \mathrm{C}=\mathrm{O}(\mathrm{C} 1 \mathrm{~s} 288.7 \mathrm{eV})$, and $\mathrm{C}-\mathrm{F}(\mathrm{C}$ $1 \mathrm{~s} 290.5 \mathrm{eV})$, coming from $\mathrm{AC}$ and the PVdF binder. ${ }^{33,35,36}$
The cathodes cycled in DME Ar, DME air, and DME:DOL Ar, present rather similar XPS peaks, although with varying intensities. The sulfur spectra show small peaks coming from $\mathrm{Li}_{2} \mathrm{~S}\left(\mathrm{~S} 2 \mathrm{p}_{3 / 2} 161.9\right.$ $\mathrm{eV})$ and $\mathrm{Li}_{2} \mathrm{~S}_{2}\left(\mathrm{~S} 2 \mathrm{p}_{3 / 2} 163.4 \mathrm{eV}\right),{ }^{33}$ indicating some irreversibility upon charge, and more intense peaks from $\mathrm{SO}_{3}{ }^{2-}\left(\mathrm{S}_{2} \mathrm{p}_{3 / 2} 166.9 \mathrm{eV}\right)$ and $\mathrm{SO}_{4}{ }^{2-}\left(\mathrm{S} 2 \mathrm{p}_{3 / 2} 168.9 \mathrm{eV}\right),{ }^{37}$ due to reactions with nitrate in the electrolyte. ${ }^{29,38}$ There is no visible sign of neutral sulfur, indicating that sulfur is not fully oxidized back to $S_{8}$. The XPS peaks of C were the same as observed in the pristine cathode, with the caveat that the $\mathrm{C}=\mathrm{O}$ peak was sharper, suggesting some reaction between $\mathrm{C}$ and the nitrate. In some of the spectra, a small amount of TFSI ${ }^{-}$ is detected as well (C 1s $293.1 \mathrm{eV}$ ). ${ }^{35}$ However, most importantly, the spectrum of the electrode cycled in DME:DOL air shows some striking differences. First, in the sulfur spectrum, no peaks associated to $\mathrm{Li}_{2} \mathrm{~S}$ or $\mathrm{Li}_{2} \mathrm{~S}_{2}$ are observable, but only those related to $\mathrm{SO}_{3}{ }^{2-}$ and $\mathrm{SO}_{4}{ }^{2-}$. Another peak is also present, which is attributed to C-S bonds $\left(\mathrm{S} 2 \mathrm{p}_{3 / 2} 169.7 \mathrm{eV}\right) .{ }^{39}$ On the carbon side, there is no peak related to the binder's C-F bond. The peak related to $\mathrm{C}-\mathrm{H}$ is much more intense and slightly shifted to lower binding energies, and the peak attributed to $\mathrm{C}=\mathrm{O}$ is still present. The electrode was then subjected to sputtering in order to remove the top layer shown in the SEM image (Figure S6). As a result, the sulfur and carbon XPS spectra show the same general features as the other cathodes, e.g., the C-F peak of the binder becomes visible again. This is a substantial proof that the spectrum of the unsputtered electrode contains only peaks related to the passivation layer. The more intense $\mathrm{C}-\mathrm{H}$ peak, then, is to be associated with the deposition of the alkoxides formed by the ester decomposition (see mechanism in Figure 4), which also explains the binding energy shift. Analogously, the $\mathrm{C}=\mathrm{O}$ peak is due to the thiocarboxylate rather than oxidized AC, since the latter is covered by the passivation layer. This is also evidenced by the presence of a C-S peak in the sulfur spectrum. The appearance of formate and alkoxides is also in agreement with previous results in DOL-based electrolytes, ${ }^{17,29}$ further reinforcing the mechanisms proposed here.

\section{Conclusions}

In summary, the effect of dissolved $\mathrm{O}_{2}$ (from dry air) in the stateof-the-art electrolyte for Li-S batteries (1 M LiTFSI, $0.25 \mathrm{M} \mathrm{LiNO}_{3}$ in 
DOL:DME) was investigated. It was observed that $\mathrm{O}_{2}$ has a negative impact on the cells. Through post mortem analysis, it was possible to determine the products of electrolyte decomposition, and, in turn, indirectly determine the mechanism of decomposition. It was also shown how the proposed reactions affect the sulfur electrochemistry, and lead to increased capacity fading, which further strengthening the proposed mechanism.

Briefly, linear solvents, such as DME, are more resistant to decomposition by oxygen species, while DOL undergoes catalytic ringopening reactions leading to fast solvent depletion. The cyclability of sulfur is affected by this decomposition of DOL (which starts at the anode side, before the cell is cycled). One proposed path of decomposition is radical-catalyzed isomerization of DOL, leading to the formation of esters, which react with the polysulfides. Such reaction increases the formation of trisulfur radical anion, electrochemically detected as the increased capacity of the sloping region during discharge. While this reaction eventually consumes all available active material, it also increases the capacity during the first discharge compared to ordinary electrolytes. This could also be determined by XPS of the cycled cathodes, which showed presence of thyocarboxylate species.

Finally, DOL was shown to aid in the SEI formation in cells containing $\mathrm{LiNO}_{3}$ as additive. DOL polymerizes on the anode, forming a more stable SEI than the one formed by only nitrate, as determined by EIS. Still, cells with and without DOL in the electrolyte provided similar specific capacity and capacity retention upon cycling. This suggests that, at least for the limited number of cycles investigated here, the presence of DOL is not imperative to obtain good capacity retention.

These results are especially important when investigating new additives to use in $\mathrm{Li}-\mathrm{S}$, for example, since, as is the case for $\mathrm{LiNO}_{3}$, they could generate radicals in the electrolyte. These findings are also relevant to the field of $\mathrm{Li}-\mathrm{O}_{2}$ batteries, where these ether-based electrolytes are also used.

\section{Acknowledgments}

The authors thank Prof. Dr. Rolf Jürgen Behm and Dr. Thomas Diemant for performing XPS measurements. LL acknowledge the financial support from $\mathrm{CNPq} / \mathrm{Science}$ without Borders program.

\section{References}

1. D. A. Boyd, "Schwefel in Der Modernen Materialwissenschaft," Angew. Chemie, 2 (2016).

2. D. Bresser, S. Passerini, and B. Scrosati, "Recent Progress and Remaining Challenges in Sulfur-Based Lithium Secondary Batteries - a Review," Chem. Commun., 49(90), 10545 (2013)

3. J. Gao, M. A. Lowe, Y. Kiya, and H. D. Abruña, "Effects of Liquid Electrolytes on the Charge-Discharge Performance of Rechargeable Lithium/sulfur Batteries: Electrochemical and in-Situ X-Ray Absorption Spectroscopic Studies," J. Phys. Chem. $C, \mathbf{1 1 5}(50), 25132(2011)$

4. T. Yim, Park, M.-S. Yu, J.-S. Kim, K. J. Im, K. Y. Kim, J.-H. Jeong, G. Jo, Y. N. Woo, S.-G. Kang, K. S. al., and "Effect of Chemical Reactivity of Polysulfide toward Carbonate-Based Electrolyte on the Electrochemical Performance of Li-S Batteries," Electrochim. Acta, 107, 454 (2013).

5. Y. X. Yin, S. Xin, Y. G. Guo, and L. J. Wan, "Lithium-Sulfur Batteries: Electrochemistry, Materials, and Prospects," Angew. Chemie - Int. Ed., 52(50), 13186 (2013).

6. S. S. Zhang, "Liquid Electrolyte Lithium/sulfur Battery: Fundamental Chemistry, Problems, and Solutions," J. Power Sources, 231, 153 (2013).

7. Y. Diao, K. Xie, S. Xiong, and X. Hong, "Shuttle Phenomenon-The Irreversible Oxidation Mechanism of Sulfur Active Material in Li-S Battery," J. Power Sources, 235, 181 (2013).

8. Z. Lin, Z. Liu, W. Fu, N. J. Dudney, and C. Liang, "Phosphorous Pentasulfide as a Novel Additive for High-Performance Lithium-Sulfur Batteries," Adv. Funct. Mater. 23(8), 1064 (2013)

9. F. Wu, J. T. Lee, N. Nitta, H. Kim, O. Borodin, and G. Yushin, "Lithium Iodide as a Promising Electrolyte Additive for Lithium-Sulfur Batteries: Mechanisms of Performance Enhancement," Adv. Mater, 27(1), 101 (2015).

10. X. Liang, Z. Wen, Y. Liu, M. Wu, J. Jin, H. Zhang, and X. Wu, "Improved Cycling Performances of Lithium Sulfur Batteries with LiNO 3-Modified Electrolyte," $J$ Power Sources, 196(22), 9839 (2011).
11. B. D. McCloskey, D. S. Bethune, R. M. Shelby, G. Girishkumar, and A. C. Luntz, "Solvents' Critical Role in Nonaqueous Lithium-Oxygen Battery Electrochemistry," J. Phys. Chem. Lett., 2(10), 1161 (2011).

12. Q. Wang, Zheng, J. Walter, E. Pan, H. Lv, D. Zuo, P. Chen, H. Deng, Z. D. Liaw, B. Y. Yu, X. al., and ",Direct Observation of Sulfur Radicals as Reaction Media in Lithium Sulfur Batteries," J. Electrochem. Soc., 162(3), A474 (2015).

13. M. Cuisinier, P. E. Cabelguen, S. Evers, G. He, M. Kolbeck, A. Garsuch, T. Bolin, M. Balasubramanian, and L. F. Nazar, "Sulfur Speciation in Li-S Batteries Determined by Operando X-Ray Absorption Spectroscopy," J. Phys. Chem. Lett., 4(19), 3227 (2013).

14. S. S. Zhang, "Effect of Discharge Cutoff Voltage on Reversibility of Lithium/Sulfur Batteries with $\mathrm{LiNO}_{3}$-Contained Electrolyte," J. Electrochem. Soc., 159(7), A920 (2012).

15. J. Christensen, P Albertus, R. S. Sanchez-Carrera, T. Lohmann, B. Kozinsky, R. Liedtke, J. Ahmed, and A. Kojic, "A Critical Review of Li/Air Batteries," J. Electrochem. Soc., 159(2), R1 (2012).

16. N. Imanishi and O. Yamamoto, "Rechargeable Lithium-Air Batteries: Characteristics and Prospects," Mater. Today, 17(1), 24 (2014).

17. S. A. Freunberger, Y. Chen, N. E. Drewett, L. J. Hardwick, F. Bardé, and P. G. Bruce, "The Lithium-Oxygen Battery with Ether-Based Electrolytes," Angew. Chemie Int. Ed., 50(37), 8609 (2011).

18. Mc Murry, J. Ester Cleavages via S N 2-Type Dealkylation. In Organic Reactions, John Wiley \& Sons, Inc.: Hoboken, NJ, USA, 2011, Vol. 24, pp 187.

19. M. Cuisinier, C. Hart, M. Balasubramanian, A. Garsuch, and L. F. Nazar, "Radical or Not Radical: Revisiting Lithium-Sulfur Electrochemistry in Nonaqueous Electrolytes," Adv. Energy Mater., 5(16), 1 (2015).

20. H. Yoshida and H. Matsuura, "Density Functional Study of the Conformations and Vibrations of 1, 2-Dimethoxyethane," J. Phys. Chem. A, 102(16), 2691 (1998).

21. J. Makarewicz and T. Ha, "Ab Initio Study of the Pseudorotation in 1,3-Dioxolane," J. Mol. Struct., 599(1-3), 271 (2001).

22. J. Read, "Characterization of the Lithium/Oxygen Organic Electrolyte Battery," $J$ Electrochem. Soc., 149(9), A1190 (2002).

23. Y. L. Berman, Y. B. Lyudvig, V. A. Ponomarenko, and S. S. Medvedev, "Mechanism of the Polymerization of 1,3-Dioxolane," Polym. Sci. U.S.S.R., 11(1), 225 (1969).

24. M. Okada, Y. Yamashita, and Y. Ishii, "Polymerization of 1,3-Dioxolane," Makromolekulare, (1964), 196.

25. W. J. Bailey, "Free Radical Ring-Opening Polymerization," Die Makromol. Chemie, 13(S19851), 171 (1985).

26. D. Aurbach, E. Pollak, R. Elazari, G. Salitra, C. S. Kelley, and J. Affinito, "On the Surface Chemical Aspects of Very High Energy Density, Rechargeable Li-Sulfur Batteries," J. Electrochem. Soc., 156(8), A694 (2009).

27. P. G. Zambonin, "Oxide Chemistry and Electroreduction of $\mathrm{NO}_{3}-$ in Molten Alkali Nitrates," J. Electroanal. Chem. Interfacial Electrochem., 24(2-3), 365 (1970).

28. D. Aurbach, O. Youngman, and P. Dan, "The Electrochemical Behavior of 1,3dioxolane-LiClO4 solutions-II. Contaminated Solutions," Electrochim. Acta, 35(3), 639 (1990).

29. D. Aurbach, E. Pollak, R. Elazari, G. Salitra, C. S. Kelley, and J. Affinito, "On the Surface Chemical Aspects of Very High Energy Density, Rechargeable Li-Sulfur Batteries," J. Electrochem. Soc., 156(8), A694 (2009).

30. D. R. Chang, S. H. Lee, S. W. Kim, and H. T. Kim, "Binary Electrolyte Based on Tetra(ethylene Glycol) Dimethyl Ether and 1,3-Dioxolane for Lithium-Sulfur Battery," J. Power Sources, 112(2), 452 (2002).

31. W. Wang, Y. Wang, Y. Huang, C. Huang, Z. Yu, H. Zhang, A. Wang, and K. Yuan, "The Electrochemical Performance of Lithium-Sulfur Batteries with LiClO 4 DOL/DME Electrolyte," J. Appl. Electrochem., 40(2), 321 (2010).

32. S. S. Zhang, "Role of $\mathrm{LiNO}_{3}$ in Rechargeable Lithium/sulfur Battery," Electrochim. Acta, 70, 344 (2012)

33. M. Helen, M. A. Reddy, T. Diemant, U. Golla-Schindler, R. J. Behm, U. Kaiser, and M. Fichtner, "Single Step Transformation of Sulphur to $\mathrm{Li}_{2} \mathrm{~S}_{2} / \mathrm{Li}_{2} \mathrm{~S}$ in Li-S Batteries," Sci. Rep., 5, 12146 (2015).

34. A. S. Manocha and R. L. Park, "Flotation Related ESCA Studies on PbS Surfaces," Appl. Surf. Sci., 1(1), 129 (1977).

35. B. Sun, C. Xu, J. Mindemark, T. Gustafsson, K. Edström, and D. Brandell, "At the Polymer Electrolyte Interfaces: The Role of the Polymer Host in Interphase Laye Formation in Li-Batteries," J. Mater. Chem. A, 3(26), 13994 (2015).

36. D. T. Clark, W. J. Feast, D. Kilcast, and W. K. R. Musgrave, "Applications of ESCA to Polymer Chemistry. III. Structures and Bonding in Homopolymers of Ethylene and the Fluoroethylenes and Determination of the Compositions of Fluoro Copolymers," J. Polym. Sci. Polym. Chem. Ed., 11(2), 389 (1973).

37. R. V. Siriwardane and J. M. Cook, "Interactions of $\mathrm{SO}_{2}$ with Sodium Deposited on CaO,” J. Colloid Interface Sci., 114(2), 525 (1986).

38. Y. Diao, K. Xie, S. Xiong, and X. Hong, "Insights into Li-S Battery Cathode Capacity Fading Mechanisms: Irreversible Oxidation of Active Mass during Cycling," $J$. Electrochem. Soc., 159(11), A1816 (2012).

39. T. X. Carroll, D. Ji, D. C. Maclaren, T. D. Thomas, and L. J. Saethre, "Relativistic Corrections to Reported Sulfur 1s Ionization Energies," J. Electron Spectros. Relat. Phenomena, 42(3), 281 (1987).

40. L. Bai and B. E. Conway, "AC Impedance of faradaic Reactions Involving Electrosorbed Intermediates: Examination of Conditions Leading to Pseudoinductive Behavior Represented in Three-Dimensional Impedance Spectroscopy Diagrams," $J$. Electrochem. Soc., 138(10), 2897 (1991). 